\title{
DEROGIMI NGA TË DREJTAT E NJERIUT
}

Enea Sheqi*

\section{*Inspektor, Ministria e Financave dhe Ekonomisë}

Adresë kontakti: enea.sheqi@yahoo.com

\section{Përmbledhje}

Objektivi: Objektivi i këtij punimi është të trajtojë në mënyrë të detajuar rastet e derogimit nga të drejtat e njeriut. Në këtë trajtesë synohet që të trajtohen kujfitë e lejimit nga derogimi i të drejtave të njeriut në rastet e gjendjes së jashtëzakonshme, procedura dhe përjashtimet nga ky nen.

Metoda: Metodologjia e përdorur në këtë artikull synon që të analizojë ligjin ndërkombëtar për të drejtat e njeriut, në një vështrim krahasimor me ligjin shqiptar. Gjithashtu, shpesh është ndërthurur me raste të praktikës gjyqësore të Gjykatës Europiane për të Drejtat e Njeriut, për të bërë më të kuptueshëm këtë studim.

Rezultatet: Artikulli paraqet disa gjetje mbi ligjin shqiptar për të drejtat e njeriut, si dhe rastet e shpalljes së gjendjeve të jashtëzakonshme, duke i paraprirë rasteve të mundshme të derogimit nga të drejtave të njeriut. Kështu analiza e Konventës Europiane të të Drejtave të njeriut i lejon shteteve palë që të marrin masa që i shmangen detyrimeve të konventës në përputhje me të drejtën ndërkombëtare.

Përfundimet: Në përfundim të punimit u vu re se Shqpëria ka një legjislacion të përafruar tërësisht me atë ndërkombëtar mbi të drejtat e njeriut. Mbi rastet kur mund të lejohet derogimi nga të drejtat e njeriut praktika e Gjykatës Europiane të të Drejtave të Njeriut ka unifkuar qëndrimin, duke dhënë kështu ide të qarta se kur duhet lejuar derogimi nga të drejtat e njeriut dhe kush është procedura që duhet ndjekur.

Fjalë çelës: Të drejtat e njeriut, derogim, gjendje e jashtëzakonshme, procedurë. 
Enea Sheqi

\title{
DEROGATION FROM HUMAN RIGHTS
}

\begin{abstract}
Objective: The objective of this paper is to address in detail the cases of derogation from human rights. In this article the aim is to treat the allowances of derogation from human rights in cases of emergency, and the procedure which should be followed by the state.

Method: The methodology used in this article aims to analyze international human rights law, in a comparative view with Albanian law. It is also often ass interwine ëwth the case law of the European Court of Human Rights to make this study more understandable.

Results: The article presents some findings on the Albanian human rights law as well as the cases of the proclamation of extraordinary situations, preceded by possible cases of human rights derogation. Thus, the analysis of the European Convention on Human Rights allows parties to take measures to avoid the obligations of the convention in accordance with international law.
\end{abstract}

Conclusions: At the end, it was noted that Albania has a fully approximated legislation with the international human rights law. In cases where derogation from human rights can be allowed, the practice of the European Court of Human Rights has unified the stance, giving clear ideas as to when to allow for derogation from human rights and the procedure to be followed.

Key words: Human rights, derogation, emergency situations, procedure.

\section{Hyrje}

Shtetet në mbarë botën synojnë që t’i garantojnë shtetasve të vetë të drejtat dhe liritë themelore. Për këtë arsye shtetet në Kushtetutat dhe në aktet e tyre themelore sanksionojnë shprehimisht të drejtat dhe liritë themelore të njeriut sipas standarteve ndërkombëtare. Konventa Europiane për të Drejtat e Njeriut përbën një nga instrumentat më të rëndësishëm ku janë të përcaktuara të drejtat e njeriut të cilën edhe shteti ynë e ka miratuar. Të drejtat e sanksionuara në këtë konventë i japin mundësi çdo individi që të gëzojë të drejtat bazike e liritë themelore, për të cilat shteti ka një detyrim pozitiv për t'i garantuar.

Të drejtat e njeriut përbëjnë jo vetëm vlerat dhe gurët e themelit të cdo shteti, por mbrojtja e tyre tregonë edhe angazhimin që ka cdo shtet ndaj shtetasi të tij. Zbatimi i të drejtave të njeriut, e mbrojtja e tyre nuk shtrihet vetëm në një rrafsh vertikal, atë të shtetit ndaj individëve, por edhe në atë horizontal në marrëdhëniet individ-individ. Për shkak të karakterit të tyre universal, këto të drejta janë të njohura dhe zbatohen në të gjithë botën, duke iu nënshtruar 
DEROGIMI NGA TË DREJTAT E NJERIUT

normave të pranuara në të gjitha shtetet e botës, si për shembull e drejta e jetës, e drejta për të mos u nënshtruar torturës e ndalimit degradues, ndalimi i punës së detyruar, etj.

Derogimi nënkupton një tejkalim të ligjit apo një pezullim i përkohshëm i tij që bëhet në rrethana apo kushte të caktuara të parashikuara në ligj. Në rastet e përballjes me emergjenca apo me sigurinë kombëtare për shtetet lind e domosdoshme që të marrin masa për të kapërcyer këto kërcënime, shpesh herë masa që cënojnë të drejtat e liritë civile apo politike. Për të kapërcyer shqetësimet që mund të lindin ndaj shteteve, traktatet ndërkombëtare kanë parashikuar klauzola të cilat i japin mundësi shteteve që nën përputhje me disa kritere të caktuara nga e drejta ndërkombëtare të shmangen nga disa detyrime (1). Në çdo rast kjo e drejtë e shteteve për të deroguar nga të drejtat, është një mekanizëm i përkohshëm dhe një mekanizëm që duhet të zbatohet shumë rrallë (2). Derogimi si një mjet i përkohshëm duhet të shihet periodikisht me qëllim që me mbarimin e kushteve të derogimit të rivendosen të drejtat e garantuara në Kushtetutë. Kështu përkohshmëria i përshtatet më së miri parimit të proporcionalitetit (3).

Disa herë derogimi nga të drejtat e njeriut është konsideruar nga doktrina si një mjet i cili dobëson detyrimet e ndërmarra nga aktet ndërkombëtare, që kanë për qëllim, mbrojtjen e të drejtave dhe lirive themelore.

\section{Derogimi sipas Konventës Europiane të të Drejtave të Njeriut}

Në nenin 15 të Konventës parashikohet shprehimisht se: "Në rast lufte, ose në rast të një rreziku tjetër publik që kërcënon jetën e kombit, cdo palë kontraktuese mund të marrë masa që nuk u pëmbahen detyrimeve të parashikuara nga kjo konventë, vetëm për sa e kërkon situata dhe me kusht që këto masa të mos jenë në kundërshtim me detyrimet e tjera që rrjedhin nga e drejta ndërkombëtare. 2. Dispozita e mësipërme nuk autorizon shmangje nga neni 2 me përjashtim të rastit të vdekjes që rrjedh nga akte të lejueshme të luftës dhe nga nenet 3,4 (paragrafi 1) dhe 7. 3. Çdo palë e lartë kontraktuese që ushtron këtë të drejtë shmangjeje mban plotësisht të informuar Sekretarin e përgjithshëm të Këshillit të Europës për të gjitha masat e marra dhe arsyet që i kanë shkaktuar ato. Gjithashtu, ajo duhet të informojë Sekretarin e Përgjithshëm të Këshillit të Europës për datën në të cilëmn këto masa pushojnë së qëni në fuqi dhe dispozitat e Konventës vihen rishtaz në zbatim."

Duke u nisur nga analiza e nenit të mësipërm që ky derogim të jetë i lejueshëm duhet që kërkesa të plotësojë tre kushte kryesore:

- Duhet të ekzistojë një gjendje e jashtëzakonshme që kërcënon jetëën e shtetasve dhe kombit. 
Enea Sheqi

- Masat e marra për këtë situatë duhet të jenë të lidhura ngushtësisht me nevojën e situatës.

- Masat e marra duhet që të jenë në përputhje me detyrimet e tjera të shteteve ndaj normave ndërkombëtare.

Kërkesat proceduriale kërkojnë që të ekzistojë një dokument ligjor i derogimit dhe njoftimin e derogimit, i masave të marra dhe data e mbarimit të derogimit duhet t'i komunikohet Sekretarit të Përgjithshëm të Këshillit të Europës (4).

Duke ju referuar kushtit të parë sipas Konventës Europiane të të Drejtave të njeriut shtetet mund të arrijnë që të bëjnë limite mbi këto të drejta apo derogime duke u nisur së pari nga fakti që shteti mund të jetë në periudhë lufte apo përballet me një emergjencë publike. Këto mund të jenë situata të cilat ndikojnë tek popullsia dhe përbëjnë një kërcërnim ndaj jetës së komunitetit që është ndërtuar brenda shtetit. Pra në rastet kur shtetet gjenden në një situatë lufte me ndonjë shtet tjetër, apo kur janë në rastet e konflikteve të armatosura sipas të drejtës ndërkombëtare mund të bëjnë një kërkesë për derogimin nga të drejtat e njeriut që parashikohen në traktatet ndërkombëtare. Gjithashtu edhe emergjencat publike janë rastet kur krizat apo situatat që prekin popullsinë e një shteti dhe i shkaktojnë një kërcënim organizimit shoqëror të atij shteti (5).

Në analizën e kushtit të dytë që lidhet ngushtësisht me proporcionalitetin e masave të marra të cilat duhet të jenë në përputhje me nevojën e situatës së cilës e ka diktuar atë, është e rendësishme që të analizohen faktorët që kanë diktuar vendosjen e masave të tilla dhe sa është ruajtuar balanca ndërmjet masave dhe nevojës së vendosjes së tyre.

Edhe pse në çështjen Aksoy gjykata përcaktoi se shteteve kontraktuese duhet që t'i lihet një hapësirë e gjerë vlerësimi, nuk duhej të abuzohej mbi këtë çështje. Kjo pasi shtetet nuk disponojnë një diskrecion të pakufizuar, por një diskrecion që duhet të jetë në përputhje me kushtet thelbësore për shkeljen e të drejtave dhe shmangjen ndaj tyre në rrethanat e kohëzgjatjen e emergjencës publike (6).

Në lidhje me kriterin e tretë, që ka të bëjë me ndërmarrjen e masave në përputhje me detyrimet e tjera të shteteve ndaj normave ndërkombëtare, është e rëndësishme të vihet theksi në pajtueshmërinë e masave të marra ndaj akteve ndërkombëtare. Pra shteti nuk mund të përjashtojë veten e vetë nga detyrimet e tjera ndërkombëtare (7).

Neni 15 i Konventës Europiane të të Drejtave të Njeriut, inkorporon parimin e nevojës (absolutisht të nevojshme), të përbashkët për të gjitha sistemet ligjore. Shumë shtete kanë para shikuar situatën e jashtëzakonshme, duke i fuqizuar ata me marrjen e masave që në situata të tjera nuk do të ishin ligjore (8).

Në analizën e nenit 15 të Konventës të rëndësishme janë dhe dy etapat proceduriale të vendosjes së derogimit. Së pari ka të bëjë me faktin e vendosjes së gjendjes së emergjenës së 
jashtëzakonshme me anë të një akti zyrtar, ku në këtë mënyrë edhe vihet në dijeni e gjithë popullsia për vendosjen e kësaj gjendjeje. Mënyra e kryerjes së këtij veprimi është në varësi të legjislacionit të brendshëm të shteteve palë kontraktuese të konventës. Gjithashtu vendosja e një gjendjeje të tillë me anë të një akti zyrtarë e shpalljes së tij, i jep mundësinë edhe mbi mundësinë e të provuarit të kësaj gjendjeje përpara gjykatës në rast të një konflikti të mundshëm në të ardhmen. Së dyti e rëndësisshme është dhe akti procedurial i lajmërimit të Sekratarit të Përgjithshëm të Këshillit të Europës, duke e njoftuar për të gjitha masat e marra, si dhe duke argumentuar arsyet pse janë ndërmarrë këto masa. E rëndësishme është dhe njoftimi për sa kohë do të zgjasin këto masa, si dhe kur dispozitat e Konvetës do të zbatohen sërisht. Procedura e njoftimit dhe shpalljes zyrtare të derogimit është tepër e rëndësishme pasi moszbatimi i saj sjell dhe pamundësinë e zbatimit të nenit 15 të Konvetës. Kështu Komisioni është shprehur se mungesa e një njoftimi zyrtar dhe publik i derogimit nuk sjell zbatimin e nenit 15 të Konventë dhe shteti i cili nuk e zbaton procedurën është në shkelje të Konvetës si një palë kontraktore (9).

Megjithatë Konventa ka disa të drejta ndaj të cilës nuk mund të derogohen. Duke u nisur nga e drejta e jetës si një e drejtë themelore e duke vazhduar deri tek e drejta për të mos iu nënshtruar torturës apo trajtimit çnjërëzor e degradues dhe ndalimi i skllavërisë apo robërisë (10). Nga e drejta e jetës bëhet një përjashtim në rastet kur këto akte (vdekja), vijnë si pasojë e akteve të ligjshme të luftës (11). Gjithashtu një e drejtë tjetër e cila nuk mund të derogohet është dhe ajo e mosdenimit pa ligj. Pra edhe në rastet e derogimit askush nuk mund të dënohet për një veprim apo mosveprim, i cili në momentin kur është kryer nuk përbënte krim në të drejtën e brendshme apo atë ndërkombëtare. Gjithashtu nuk mund të jepet një dënim më i rëndë se ai i parashikuar në ligj. Ky parashikim nuk zbatohet në rastet kur vepra që ka kryer personi është konsideruar si vepër penale, sipas parimeve të përgjithshme të kombeve të qytetëruara (12). Gjithashtu sipas protokolleve të shtuara të Konventës nuk mund të kemi derogim nga ndalimi i dënimit me vdekje në kohë paqeje sipas nenit 1 të protokollit numër 6 , ndalimit të dënimit me vdekje në të gjitha rrethanat sipas nenit 1 të protokollit numër 13 si dhe ndalimit për t’u dënuar dy herë për të njëjtën vepër sipas nenit 4 të protokollit numër 7 të Konventës Europiane të të Drejtave të Njeriut.

Duhet thënë që zbatimi i derogimit nga ana e shteve kontraktore të Konventës nuk mbetet pa asnjë lloj filtri apo rishikimi. Ankesat mund të ngrihen si nga personat fizikë si një shkelje e të drejtave të njeriut në Gjykatë, ashtu si nga shtetet anëtare të Konventës që mund të referojnë në institucionet përbërëse të Këshillit të Europës për nisjen e një procedure mbikqyrje.

Një nga rastet e derogimit është ai nga ana e Greqisë vendosur në vitin 1967. Kjo u vendos pas rrëzimit të regjimit në Greqi nga një qeveri revolucionare. Danimarka, Norvegjia, Suedia dhe Hollanda kryen një aplikim në Komisionin Europian të të Drejtave të Njeriut, në të cilën argumentonin se Greqia kishte kryer një sërë shkeljesh nga detyrimet ndërkombëtare e përkatësisht nenit 15 të Konventës. Në procedurën e mbikëqyrjes së realizaur nga Komisioni u vu re se emergjenca publike 
Enea Sheqi

që cënonte jetën e qytetarëve në realitet nuk ekzistonte. Kjo pasi në Greqi nuk ekzistonte asnjë rrezik aktual, apo që të cënonte jetën e banorëve të shteti e as rendin shoqëror në një shoqëri të organizuar. Kështu Greqia u gjet në shkelje të Konventës, duke mos i garantuar një sërë të drejtash qytetarëve të saj, e duke i shkelur ato me qëllim (13).

Edhe pse vihet re se shtetet në përcaktimin e gjendjes së emergjencës si dhe kur mund të derogohet, shtetet i nënshtrohen një testi se si duhet të përcaktohen këto masa për të qenë sa më proporcionale. Kështu marzhi i shteteve duhet parë nën prizmin e kushteve të përcaktuara nga gjykata dhe nga Konventa.

\section{Kuadri ligjor i derogimit në Shqipëri}

Në qoftë se do të bënim një analizë të legjislacionit shqiptar do të vinim re se për marrjen e masave të jashtëzakonshme është një procedurë e parashikuar që në Kushtetutë. Kështu tregohet rëndësia e këtyre masave dhe një proces strikt që duhet ndjekur në rastet kur jemi përpara një situate të tillë.

Kështu masat e jashtëzakonshme mund të vendosen për shkak të gjendjes së luftës, gjendjes së jashtëzakoshme, apo gjendjes së fatkeqësive natyrore, duke zgjatur për aq kohë sa zgjat kjo gjendje (14).

Veprimtaria e organeve të administratës publike si dhe masa e kufizimit të të drejtave të njeriut gjatë kësaj periudhe duhet që të përcaktohet me ligj. Në këtë ligj duhet që të përcaktohen parimet, fushat dhe mënyrën e kompensimit të humbjeve që vijnë si rezultat i kufizimit të të drejtave dhe lirive gjatë marrjes së masave të jashtëzakonshme (15).

Masat e ndërmarra kurdoherë duhet që të jenë proporcionale e t'i përshtaten nevojave të gjendjes, duhet të jenë në përpjesëtim me shkallën e rrezikut dhe duhet të synojnë rivendosjen sa më të shpejtë të kushteve për funksionimin normal të shtetit (16). Pra një kufizim i të drejtave të njeriut duhet që të jetë në përputhje me gjendjen që e dikton atë duke munduar që të ruhet balanca ndërmjet interesit publik e atij privat.

Një nga rastet e mundshme ku mund të vendoset masa e gjendjes së jashtëzkonshme është ajo e një agresioni të armatosur ku Presidenti i Republikës, me kërkesë të Këshillit të Ministrave, shpall gjendjen e luftës e në këtë mënyrë hyjnë në fuqi masat e gjendjes së jashtëzkonshme. Në rast kërcënimesh të jashtme ose kur detyrimi për mbrojtje të përbashkët buron nga një marrëveshje ndërkombëtare, Kuvendi, me propozim të Presidentit të Republikës, shpall gjendjen e luftës, vendos gjendjen e mobilizimit dhe të çmobilizimit të përgjithshëm ose të pjesshëm (17).

Masat e jashtëzkonshme mund të nevojiten edhe kur jemi në rast rreziku për rendin kushtetues dhe për sigurinë publike, Kuvendi, me kërkesë të Këshillit të Ministrave, mund të vendosë në një pjesë ose në të gjithë territorin e shtetit gjendjen e jashtëzakonshme, e cila zgjat për aq kohë sa vazhdon rreziku, por jo më shumë se 60 ditë. Ky afat mund të zgjatet me pëlqim të Kuvendit çdo 30 ditë, për një periudhë jo më shumë se 90 ditë (18).

Fatkeqësitë natyrore apo aksidentet teknologjike, mund të kërkohen që të parandalohen pasojat që 
DEROGIMI NGA TË DREJTAT E NJERIUT

mund të vijnë nga një ndodhi e tillë mund të bëjë që Këshilli i Ministrave të vendosë, për një periudhë jo më të gjatë se 30 ditë, gjendjen e fatkeqësisë natyrore në një pjesë ose në të gjithë territorin e shtetit (19).

Ajo që është e rëndësishme është fakti se një kategori të drejtash nuk mund që të cënohen e as mund të kuzohen për vetë rëndësinë e karakterin që kanë këto të drejta. Në nenin 175 të Kushtetutës së Republikës përcaktohen në mënyrë të qartë të drejtat që nuk mund të kufizohen. Kështu nuk mund të kufizohet në asnjë rast barazia para ligjit dhe asnjë person nuk mund të diskriminohet për asnjë lloj motivi. E drejta e shtetësisë dhe e pakicave kombëtare nga ana tjetër nuk mund të kufizohet dhe as mundet që të vendoset një gjendjeje të tillë. E drejta e jetës është e drejta më e rëndësishme e nuk mund të kufizohet kurrsesi, as në vendosjen e një mase të tillë. Gjithashtu liria e ndërgjegjes dhe e fesë si dhe fakti që askush nuk mund t'i nënshtrohet torturës apo trajtimeve degraduese është e garantuar edhe në vendosjen e masave të tilla.

Në vendosjen e masave të tilla askush nuk mund të akuzohet ose të deklarohet fajtor për një vepër penale, e cila nuk konsiderohej e tillë me ligj në kohën e kryerjes së saj, me përjashtim të veprave, të cilat në kohën e kryerjes së tyre, përbënin krime lufte ose krime kundër njerëzimit sipas së drejtës ndërkombëtare. Nuk mund të jepet një dënim më i rëndë se ai që ka qenë parashikuar me ligj në kohën e kryerjes së veprës penale. Gjithashtu në këtë periudhë nuk mund të cënohet as parimi i prezumimit të pafajsisë si dhe të drejtat e personit gjatë procesit penal të parashikuara në nenin 31 të Kushtetutës. Parimi i mos vetëinkriminimit si dhe parimi për t'u dëgjuar përpara gjykatës e për t'u dënuar pasi janë mbledhur të gjitha provat e nevojshme, ashtu si dhe e drejta për të mos u dënuar dy herë për të njëjtën vepër nuk mund të cënohen as në këtë periudhë. Në këtë periudhë ruhet gjithashtu e drejta e shtetasve shqiptarë për të mos u dëbuar jashtë territorit të Shqipërisë. E drejta e pronës nuk mund të cënohet në vendosjen e masave të jashtëzakonshme me përjashtim të shpronësimeve të cilat mund të kufzohet e drejta për të marrë një shpërblim të drejtë në një rast të tillë.

E drejta për të pasur një proces të rregullt ligjor është një nga të drejtat kryesore të cilat nuk mund të kufzohen kurrsesi gjatë vendosjes së kësaj gjendjeje, pasi lidhet ngushtësisht me të drejtat themelore të njeriut të lidhura me këtë të drejtë, ashtu si dhe e drejta për t'u ankuar ndaj vendimi qoftë ky gjyqësor apo i një organi publik.

E rëndësishme është edhe fakti që edhe në këtë periudhë shteti ruan angazhimet për mbrojtjen e kategorive të vecanta si të rinjtë, fëmijët e gratë shtatzëna ashtu dhe të drejtat për kujdes shëndetsor e sigurime shoqërore.

Ndër të drejtat që mund të kufizohen mund të përmendim paprekshmërinë e banesës e kontrollet që kryen ndaj saj. Gjithashtu kontrollet vetjake apo e drejta për të lëvizur lirisht apo për të ndryshuar vendbanim gjatë kësaj periudhe mund të kufizohen me ligj të caktuar. Të drejta të tjera që mund të kufizohen janë edhe e drejta e personave për të nxjerrë mjetet e jetesës me një punë të ligjshme apo liria e zgjedhjes së profesionit, ashtu si dhe të drejtat kolektive të punës si e drejta e grevës. 
Enea Sheqi

Shqipëria gjatë anëtarësimit të saj në këtë konventë ka pasur një rast ku ka bërë derogim nga të drejtat e njeriut sipas nenit 15 të Konventës Europiane të të Drejtave të Njeriut. Ky derogim është bërë në 24 korrik të vitit 1997 pas miratimit të ligjit nr. 8225 për vendosjen e gjendjes së jashtëzakoshme në të gjithë territorin e Shqipërisë. Këtij derogimi u dha fund me njoftimin e Sekretarit të Përgjithshëm në 24 tetor të vitit 1997 (20). Edhe pse ky ka qenë një nga rastet e vetme të derogimit nga të drejtat e njeriut është e rëndësishme fakti, që në këtë mënyrë është ndërtuar praktika, se si të procedohet në rastet kur gjendemi në kushtet e nenit 15 të Konventës.

\section{Përfundime}

Në rastet e përballjes me emergjenca apo me sigurinë kombëtare për shtetet lind e domosdoshme që të marrin masa për të kapërcyer këto kërcënime, shpesh herë masa që cënojnë të drejtat e liritë civile apo politike. Derogimi është një e drejtë që i lind shteteve si palë kontraktuese në një apo disa traktate me karakter ndërkombëtar, nëpërmjet të cilit palët mund të shmangin një apo disa të drejta në rastet e emergjencës apo gjendjes së jashtëzakonshme.

Konventa Europiane e të Drejtave të Njeriut ka parashikuar në nenin 15 të saj disa nga rastet kur palët kontraktuese mund të derogojnë nga këto të drejta. Në nen nuk janë parashikuar vetëm garancitë me natyrë materiale, duke dhënë një përcaktim të qartë të rasteve kur mund të derogohen, por edhe atyre me natyrë proceduriale, duke përfshirë në mënyrë të detajuar procedurën sesi mund të derogohet e hapat që duhet të ndiqen.

Shqipëria si palë kontraktuese e Konventës Europiane së të Drejtave të Njeriut, ka parashikuar të njëjtat garanci legjislative që konventa parashikon në tekstin e saj. Kështu është e parashikuar qartë në Kushtetutë se kur mund të derogohet, kush janë të drejtat ndaj të cilat mund të hiqet dorë si dhe kush është procedura që duhet ndjekur në rastet e tilla.

\section{Referenca}

1. Hafner-Burto E.M., Helter R.H, Fariss. C.J, Emergency and Escape: Explaining Derogations from Human Rights Treaties, International Organization 65, Fall 2011, fq.676.

2. Hafner-Burton E.M., Helter R.H, Fariss. C.J, Emergency and Escape: Explaining Derogations from Human Rights Treaties, International Organization 65, Fall 2011, fq.16

3. Brannigan And Mcbride V. The United Kingdom, Nr. 14553/89; 14554/89, Vendim i Gjykatës Europiane të të Drejtave të Njeriut, 25 Maj 1993.

4. Mucollari O., Të drejtat Ndërkombëtare të Njeriut, Migrealb, Tiranë 2015, fq.89.

5. Lawless v Ireland, Nr.332/57, Vendim i Gjykatës Europiane të të Drejtave të Njeriut, 1 Korrik 196. 
6. Aksoy v Turqisë, Nr.21987/93, Vendim i Gjykatës Europiane të të Drejtave të Njeriut, 18 Dhjetor 1996.

7. Mucollari O., Të drejtat Ndërkombëtare të Njeriut, Migrealb, Tiranë 2015, fq.90.

8. Mucollari O., Të drejtat Ndërkombëtare të Njeriut, Migrealb, Tiranë 2015, fq.87.

9. Qipro v Turqisë, Raport i Komisionit Europian për të Drejtat e Njeriut, 4 tetor 1983.

10. Derogation from human rights in emergency situations The suspension of certain human rights under the ECHR on grounds of counter-terrorism measures 25.11.2016, fq.28.

11. Neni $15 / 2$ i Konventës Europiane të të Drejtave të Njeriut.

12. Neni 7 i Konventës Europiane të të Drejtave të Njeriut.

13. https://www.echr.coe.int/Documents/FS_Derogation_ENG.pdf

14. Neni 170/1 i Kushtetutës së Republikës së Shqipërisë.

15. Neni 170/2 dhe 170/3 i Kushtetutës së Republikës së Shqipërisë.

16. Neni 170/4 i Kushtetutës së Republikës së Shqipërisë.

17. Neni 171 i Kushtetutës së Republikës së Shqipërisë.

18. Neni 173 i Kushtetutës së Republikës së Shqipërisë.

19. Neni 174 i Kushtetutës së Republikës së Shqipërisë.

20. https://www.coe.int/en/web/conventions/search-on-states/-/conventions/declarations 